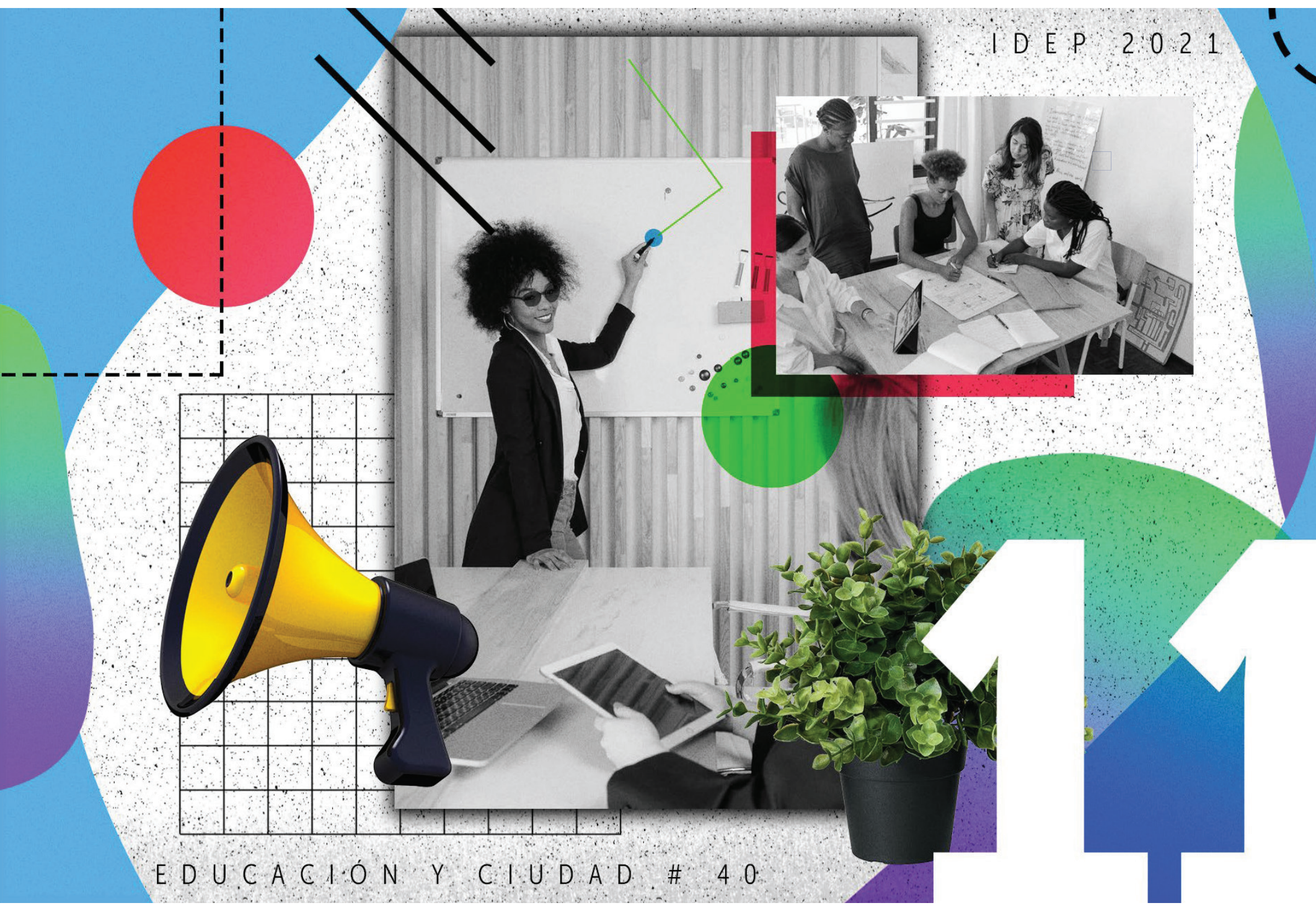

\title{
Conflicto armado y biodiversidad: una mirada desde la ciudadanía cultural y la educación ${ }^{1}$
}

ARMED CONFLICT AND BIODIVERSITY: A LOOK FROM CULTURAL CITIZENSHIP AND EDUCATION CONFLITO ARMADO E BIODIVERSIDADE: UM OLHAR DA CIDADANIA CULTURAL E DA EDUCAÇÃO Viviana Suárez Galvis Martha Cecilia Herrera 
Viviana Suárez Galvis ${ }^{2}$

Martha Cecilia Herrera ${ }^{3}$
2. Doctoranda en Educación, Universidad Pedagógica Nacional; Magíster en Pedagogía de la Lengua Materna; Docente de la Secretaría de Educación Distrital; Miembro del grupo de investigación Educación y Cultura Política; ORCID: https://orcid.org/0000-0002-52533664; CvLAC: https://scienti.minciencias.gov.co/cvlac/visualizador/generarCurriculoCv. do?cod_rh=0000023142; correo electrónico:vsuarezg@educacionbogota.edu.co

3. Doctora en Filosofía e Historia de la Educación, Universidad Estadual de Campinas (Sao Paulo, Brasil); Magíster en Historia, Universidad Nacional; Profesora Emérita y Catedrática Titular, Universidad Pedagógica Nacional; Fundadora del grupo de investigación Educación y Cultura Política; CvLAC: http://scienti.colciencias.gov.co:8081/cvlac/visualizador/ generarCurriculoCv.do?cod_rh=0000036650; Google Scholar: https://scholar.google.es/ citations?hl=es\&user=ZbVZ7CcAAAA); ORCID: orcid.org/0000-0003-4170-7822; correo electrónico: malaquita10@gmail.com

Citar artículo como:

Suárez, V., y Herrera, M. (2021, Enero-Junio). Conflicto armado y biodiversidad: una mirada desde la ciudadanía cultural y la educación. Revista Educación y Ciudad, No. 40, pp. 165-177. //doi. org/10.36737/01230425.n40.2021.2463

DOI: https://doi.org/10.36737/01230425.n40.2021.2463

Fecha de recepción: 22 de julio de 2020 / Fecha de aprobación: 4 de noviembre de 2020

\section{Resumen}

El presente artículo explora las relaciones entre conflicto armado y biodiversidad, considerando los aportes de la ciudadanía cultural, así como el lugar de la educación en la formación de ciudadanos éticamente responsables con el ambiente. Respecto a la ciudadanía cultural, se exponen los hechos políticos y cambios sociales que han hecho plausible históricamente la transformación de la noción y, en tal medida, el reconocimiento de nuevas formas de ciudadanía que pueden responder más apropiadamente a las exigencias de un mundo divergente en términos políticos y culturales, con grandes desafíos en el campo ecológico.

Palabras clave: Conflicto armado, biodiversidad, ciudadanía cultural, educación.

\section{Abstract}

This article explores the relationships between the armed conflict and biodiversity, considering for this the contributions of cultural citizenship, as well as the place of education in the formation of ethically responsible citizens with the environment. About the cultural citizenship, the political facts and social changes that have historically made the transformation of this notion plausible and, to that extent, the recognition of new forms of citizenship that can respond more appropriately to the demands of a world are exposed. divergent in political and cultural terms and with great challenges in the ecological field.

Keywords: Armed conflict, biodiversity, cultural citizenship, education.

\section{Resumo}

Este artigo explora as relações entre conflito armado e biodiversidade, considerando para isso as contribuições da cidadania cultural e o lugar da educação na formação de cidadãos eticamente responsáveis com o meio ambiente. No que diz respeito à cidadania cultural, são expostos os eventos políticos e as mudanças sociais que historicamente tornaram plausível a transformação dessa noção e, nessa medida, o reconhecimento de novas formas de cidadania que respondem melhor às demandas de um mundo. divergentes em termos políticos e culturais e com grandes desafios no campo ecológico.

Palavras-chave: Conflito armado, biodiversidade, cidadania cultural, educação.

\footnotetext{
$1 \quad$ Este artículo presenta los avances del proyecto de investigación doctoral titulado Subjetividades de los niños y niñas en contextos de conflicto armado: sentidos y emocionalidades desde la poesía, desarrollado en el marco del Doctorado Interinstitucional en Educación de la Universidad Pedagógica Nacional.
} 


\section{Introducción}

$\mathrm{C}$ olombia, junto a otros países de América Latina, ha experimentado situaciones de violencia política y conflicto armado que han dejado miles de víctimas, desapariciones forzadas, crímenes selectivos, asesinato de líderes sociales y ambientalistas, desplazamiento forzado y reclutamiento de menores de edad, entre otros hechos que en su mayoría no han sido resueltos. Además, el conflicto armado ha desencadenado un interés específico por los recursos naturales que ha dejado impactos ambientales de diferente orden:

A lo largo de más de cinco décadas, las disputas por los recursos naturales y los conflictos socioambientales han estado entrelazadas con la violencia de formas muy diversas [...] la puja por las rentas sobre recursos naturales valiosos ha sido una de las causas y consecuencias del conflicto (Rodríguez, Rodríguez y Durán, 2017, p. 11).

En todas las etapas del conflicto armado se han presentado afectaciones socio-territoriales complejas que van, desde la destrucción a los recursos naturales, hasta un impacto desmedido sobre las condiciones productivas tradicionales y el despojo de los espacios vitales de quienes, por una u otra razón, han estado en medio de la guerra. El conflicto armado "erosiona el tejido social y político que protege la biodiversidad" (Hanson, 2019, párr. 3), llevando al aumento de la producción de narcóticos, la contaminación y degradación de terrenos, la extracción de recursos naturales (madera, diamantes, oro, vida silvestre), emisiones de gases de efecto invernadero y el aumento de la caza y la deforestación.

Estos efectos sobre la biodiversidad ponen lo ecológico como un problema sustancial de la modernidad y de los debates actuales acerca de la ciudadanía, pues trae al escenario público la discusión sobre si el concepto de ciudadanía defendido por los modelos tradicionales (liberal, republicano) cumple con las exigencias políticas de un mundo globalizado y, al tiempo, polarizado y fragmentado. Estas situaciones sociales, asociadas muy de cerca con los problemas ambientales, exigen un ciudadano que no solo sea receptor y defensor de derechos, sino que lleve a cabo prácticas de vida comunitaria respetuosas con el ambiente y con el otro.

Podría decirse que se trata de hallar las articulaciones ético-políticas entre los registros ecológicos, las relaciones sociales y la subjetividad humana, tratando de enfocar estas relaciones desde los procesos educativos asociados con la ética ambiental, entendiendo que no "somos meros consumidores de conocimientos o encantamientos bioculturales, sino que somos actores dentro de las historias y tramas de convivencia biocultural" (Rozzi, Draguicevic, Arango, Sherriffs, Ippi, Anderson, Acevedo, Plana, Cortés y Massardo, 2005, p. 25) y que, como tal, requerimos de un cambio en el tipo de interacciones entre el sujeto y su entorno, en función de la protección de la vida, de los territorios y de los sistemas tradicionales de producción, entendiendo la biodiversidad como un bien común.

El discurso de la biodiversidad dentro de la educación parece, en tal orden, instituir una cultura de la conservación, a través de la formación de ciudadanos con la capacidad de reflexionar sobre las distintas dimensiones implicadas en esta problemática relacionada, en casos como Colombia, con los efectos del conflicto armado, así como con ayudar a generar y establecer dinámicas asentadas en el desarrollo sostenible, entendido como la capacidad para preservar y usar adecuadamente los recursos 
naturales, al satisfacer las necesidades de las generaciones actuales, pero garantizando aquellas de las generaciones futuras (Naciones Unidas, 1987).

Bajo este marco, se trata de una educación que implica el compromiso con el bienestar de los sujetos a través de la exigencia por el cumplimiento de los Derechos Humanos, es decir, enfatizando en el aprendizaje crítico, solidario y propositivo frente a las injusticias sociales y ambientales, respetuosa con la diversidad y la biodiversidad. Con tal horizonte, el presente artículo retomará varios elementos para reflexionar sobre esta problemática; en ese sentido, se abordarán, en primer lugar, algunos aspectos de la ciudadanía y su ampliación, desde el punto de vista histórico, hacia la ciudadanía cultural, incluida la ecológica; en segundo lugar, se profundizará en las implicaciones del conflicto armado colombiano respecto a la biodiversidad para, en tercer lugar, adelantar algunas consideraciones que permitan pensar la educación como un campo propicio para fortalecer el encuentro ético con la biodiversidad; finalmente, se incluyen algunas conclusiones generales.

\section{Ciudadanía cultural y ecológica}

Durante los últimos siglos, la noción de ciudadanía ha recobrado interés en las reflexiones de las ciencias sociales y humanas. Las luchas de diferentes grupos y movimientos sociales que reclaman el reconocimiento de sus identidades y particularidades, así como las crisis sufridas por los Estados modernos, ponen en la discusión contemporánea la necesidad de ampliar la idea de ciudadanía. La incorporación de nuevos matices para el análisis de este concepto es producto de las dinámicas cambiantes entre los sujetos y las estructuras de poder, las cuales demuestran que no solo bastan los dere- chos civiles, políticos y sociales reconocidos por el Estado-nación, sino que es necesario asumir los reclamos expresados en las elaboraciones teóricas de las vertientes comunitaristas, pluralistas culturales, feministas y "Queer".

La ciudadanía es una construcción histórico-social y, por lo tanto, su acepción ha estado marcada por factores políticos, sociales, económicos y culturales que han dado paso a redefiniciones complejas. En el siglo XVIII, gracias al pensamiento ilustrado, se produce un surgimiento de la cultura de los Derechos Humanos y la democracia, de los cuales se desprenden dos modelos políticos que se han establecido como modos diferentes de comprender a los sujetos, la sociedad y las estructuras de poder: el modelo liberal y el republicano.

El modelo liberal reivindicó los derechos sociales de los ciudadanos mediante el establecimiento de un estado de bienestar y asistencialista. Sin embargo, fracasó en términos de justicia y legitimación social, por la distancia entre las promesas del Estado y la posibilidad de su cumplimiento. Por su parte, el modelo republicano apuntó a la potestad del ciudadano para participar en las decisiones de orden público, pero a costa de la negación de las libertades individuales, que quedaban sometidas a la voluntad colectiva. En ambos casos, como se verá, tanto la ciudadanía como la democracia quedaron aminoradas por las restricciones a las libertades y la profundización de las desigualdades sociales; solo pequeños grupos sociales de élite lograban acceder a sus derechos de manera privilegiada, dejando de lado una gran parte de la población; los no alfabetizados, pobres, negros, mujeres, jóvenes, niños e indígenas ocupan un lugar de exclusión. 
En el siglo XX, Marshall formula la noción de ciudadanía como un estatus de pertenencia a una sociedad, que le adjudica a sus miembros el disfrute de tres tipos de derechos: civiles, políticos y sociales; así como el cumplimiento de una serie de obligaciones que permitan garantizar la convivencia cívica, como una forma de dar cuenta de las transformaciones que venían ocurriendo en este campo desde el siglo XVIII. Para Marshall, entonces, la ciudadanía abarca tres tipos de acceso a los derechos: una ciudadanía civil (derechos individuales), una ciudadanía política (derechos políticos) y una ciudadanía social (derechos económicos y sociales) (Herrera, 2006).

Si bien dentro de dicho estatus de pertenencia a una sociedad parece estar explícito el hecho de que todos sus miembros son iguales respecto a derechos y deberes sin ningún tipo de distinción; desde la aparición de la noción de ciudadanía, la gran controversia ha sido cómo lograr que los derechos dejen de ser una mera promulgación legal y pasen a ser una realización efectiva. Lo anterior supone, necesariamente, la ampliación del concepto de ciudadanía, de modo que no quede reducida a la titularidad de los derechos políticos, sino que se extienda hacia una dimensión social que permita, tanto el reconocimiento, como el disfrute efectivo de los derechos y las garantías sociales, económicas y culturales.

A esto se aúna que, en los últimos años, han surgido demandas de reconocimiento de nuevas formas de identidad que ponen en duda la posibilidad de una ciudadanía universal y heterogénea, asociada generalmente a un proyecto moderno de sujeto blanco, burgués, ilustrado, adulto y heterosexual. Varias tensiones se establecen a partir de esta cuestión. En primera instancia, el pensamiento democrático implica una latente contradicción: "está contra la tiranía en nombre de la voluntad popular pero está contra el pueblo en nombre de la razón” (Martín-Barbero, 2003, p. 4); en segunda instancia, la ciudadanía se ha asociado con la democracia, pese a que en su nombre se han trazado limitaciones a la misma. La democracia oscila entre la exclusión de lo diferente y la apelación teórica hacia su reivindicación.

Finalizado el siglo XX, se añade una nueva matriz dimensional para entender la ciudadanía, la cultural, que busca la participación democrática (equitativa) de todos los miembros de una sociedad, sin que medien condicionamientos a razón de la raza, clase social, género u orientación social. Se trata del derecho a ser diferente sin que por ello se deba vivir en un lugar periférico en términos políticos, sociales o culturales. De este modo, la ciudadanía no remite solamente al estatus de pertenencia a un Estadonación, sino a la posibilidad de pertenecer a una sociedad con todas las garantías que ello implica, sin prejuicio de la identidad o particularidad.

El reclamo de los grupos sociales considerados minoría guarda relación con la posibilidad de actuar libremente dentro de una sociedad en donde las relaciones de poder estén estructuradas en forma distinta de la que funcionan actualmente. En este marco, se pretende un Estado garante de una constitución subjetiva diversa y un ciudadano que no se limite a ser recipiente de derechos, sino sujeto preocupado por actuar bajo principios y valores basados en la pluralidad y el respeto del otro y del entorno. Además, la ciudadanía cultural remite a la posibilidad de acceder a los bienes culturales de una sociedad, tanto los de tipo material como 
los simbólicos, sin más condicionamientos que los impuestos por la propia individualidad. En estos, se incluyen las prácticas culturales y educativas, que:

[...] forjan nuevas identidades y estrategias en la formación de comunidades y pertenencias, permitiendo a la gente reclamar sus derechos públicos y privados, conduciendo a formas renovadas de relaciones sociales, obligaciones y estrategias de pertenencia y adquisición de capacidades sociales (Aceves, 1997, párr. 39).

En este contexto, y a partir de factores como la apertura económica internacional, la globalización y el uso masivo de tecnologías, se abre una posibilidad de asumir de otro modo la ciudadanía, donde el ciudadano se adapte a una realidad globalmundial y los Estados se enfrenten a los desafíos que surgen al momento de crear fórmulas para tratar a ciudadanos del mundo. Desde esta mirada, el estatus de ciudadano parece adquirirse, no solo por la pertenencia a un Estado determinado, sino mediante una titularidad universal de los derechos. Sin embargo, en el plano de la vida cotidiana, los países desarrollados utilizan la ciudadanía como mecanismo para negar derechos a los inmigrantes y tomar medidas arbitrarias para restringir sus libertades.

La búsqueda de apuestas progresistas para responder a las cuestiones mencionadas se basa en el pluralismo y la interculturalidad, pues la ciudadanía cultural remite, al mismo tiempo, a la reivindicación de la heterogeneidad y el reconocimiento de la diferencia, como a principios basados en la solidaridad y la responsabilidad a nivel global. Así, y como parte de estas apuestas, el énfasis en el componente ecológico resulta una opción necesaria. El alcance global de la crisis ambiental demuestra que tomar medidas no es asunto de un solo Estado, el deterioro progresivo del ambiente exige realizar acciones a nivel global para contrarrestar este proceso de degradación.

Considerando lo anterior, la educación ocupa un lugar determinante en la formación de ciudadanos que no se conformen con una ciudadanía pasiva, definida por la simple condición de pertenencia a una comunidad determinada, sino que, al contrario, reivindiquen los principios éticos y la construcción de una cultura política enfocada en la valoración de la pluralidad y la diferencia, así como en la responsabilidad con el ambiente. Esta forma de viabilizar la ciudadanía cultural implica un escenario de apertura para pensar a los otros (como sujetos que producen múltiples discursos, representaciones y significados del mundo) y al entorno desde la exploración ecológico-cultural.

\section{El conflicto armado y las afectaciones en la biodiversidad}

Colombia es un país extremadamente diverso, en su territorio habitan 62.829 especies, ocupa el primer lugar a nivel mundial en biodiversidad de aves y orquídeas; el segundo en plantas, anfibios, mariposas y peces dulceacuícolas; el tercero en palmas y reptiles; y el cuarto en reptiles (Amórtegui, 2020) ${ }^{4}$. Según la Convención sobre la Diversidad Biológica, firmada entre los Estados Partes el 5 de junio de 1992, la biodiversidad se define como:

\footnotetext{
La variabilidad de organismos vivos de cualquier fuente, incluidos, entre otras cosas, los ecosistemas terrestres y marinos y otros ecosistemas acuáticos y los complejos ecológicos de los que forman parte; comprende la diversidad dentro de cada especie, entre las especies y de los ecosistemas (Naciones Unidas, 1992, p. 3).
} 
De tal definición se entiende la biodiversidad como un sistema constituido por partes (especies) y niveles (organización biológica y ecosistémica), que funciona de manera articulada en un territorio determinado. Junto a ello, se puede deducir que existe una:

Relación estrecha e interdependiente con los sistemas humanos, a través de un conjunto de procesos ecológicos que son percibidos como beneficios (servicios ecosistémicos $)^{5}$ para el desarrollo de los diferentes sistemas culturales humanos en todas sus dimensiones (política, social, económica, tecnológica, simbólica, mítica y religiosa) (Ministerio de Ambiente y Desarrollo Sostenible, 2012, p. 28).

Esta forma de comprender la biodiversidad plantea unos determinados acercamientos de carácter ético, estético y, por supuesto, sociocultural. Sin embargo, ¿qué pasa con esta biodiversidad, y con sus servicios ecosistémicos, cuando el territorio está marcado por el conflicto armado?; ise logra una gestión integral de la biodiversidad cuando los territorios se configuran alrededor de unas prácticas de guerra que entran en conflicto con la preservación biológica? Diversos autores se han encargado de demostrar que existe una relación directa entre conflicto armado y biodiversidad (Cárdenas y Rodríguez, 2004; Collier y Hoeffler, 2004; Hanson, Brooks,

\footnotetext{
4 Estas cifras no pretenden reducir la biodiversidad a indicadores numéricos, buscan establecer la conexión entre el componente biológico y el componente cultural, desde la mirada del hombre sobre el entorno natural y sus componentes.
}

Da Fonseca, Hoffman, Lamoreuxy y Machlis, 2009; LeBillon, 2001; McNeely, 2003; Rettberg, Leiteritz y Nasi, 2014; Ross, 2002).

La condición de país mega diverso ha puesto a Colombia en un lugar paradójico: por un lado, esta riqueza biológica es el sostén de una gran variedad de servicios ambientales; por otro, es la fuente de las disputas entre diferentes grupos políticos que buscan ocupar y dominar los territorios donde abundan recursos naturales, porque derivan gran parte de su sustento de la explotación o el gravamen de economías extractivas, desde la coca hasta la madera, el oro y el carbón. Junto a estos factores: "la apropiación, el uso y la tenencia de la tierra han sido motores del origen y la perduración del conflicto armado".

Existe documentación que demuestra la existencia de procesos históricos que vinculan la guerra con un problema agrario: "(despojos violentos, concentración ociosa de la tierra, usos inadecuados, colonizaciones y titulaciones fallidas)" (Centro Nacional de Memoria Histórica, 2013, p. 21). Si bien no se pueden reducir los orígenes ${ }^{6}$ del conflicto a este factor, la relación causal con el problema de la tierra permite señalar la dimensión ambiental como

\footnotetext{
Los servicios ecosistémicos son los beneficios que recibe el ser humano en su interacción con la biodiversidad, dentro de los que se encuentran los servicios de aprovisionamiento: alimentos, productos forestales maderables, pieles, carne y fauna ornamental, ingredientes naturales, plantas medicinales, productos farmacéuticos y productos cosméticos, recursos genéticos y agua; servicios de regulación y soporte: regulación hídrica, almacenamiento y captura de carbono; servicios culturales: contexto ecosistémico al desarrollo cultural étnico y recreación y turismo.
} 
una de las consecuencias importantes del conflicto armado.

El concepto de "puntos críticos de la biodiversidad", introducido por investigadores australianos, aclara la conexión entre biodiversidad y conflicto armado; según Sloan, Jenkins, Joppa, Gaveauy Laurance (2014), los puntos críticos son áreas que cuentan con una diversidad biológica y cultural excepcional, pero, al mismo tiempo, tienen amenazas extremas para su preservación biológica. Por su parte, otros autores establecieron que más del $90 \%$ de los conflictos armados entre 1950 y el 2000 ocurrieron en países con sitios de importancia para la biodiversidad, y más del $80 \%$ se llevaron a cabo directamente en áreas esenciales en esta materia, es decir, en los puntos críticos (Hanson, et al., 2009). Colombia, al sufrir uno de los conflictos armados más largos y volátiles de Latinoamérica, es uno de esos puntos críticos que, por tanto, requiere de especial atención para garantizar su conservación.

En ese marco, la investigación de Negret, Sonter, Watson, Possingham, Jones, Suárez, Ochoa y Maron (2019) analiza la relación entre el conflicto armado y los patrones de deforestación, señalando que:

Deforestation was positively associated with armed conflict intensity and proximity to illegal coca plantations. A deforestation model including 14 variables was $78 \%$ accurate in predicting deforestation at a $10 \mathrm{~km} 2$ resolution. On their own armed conflict and coca cultivation had a notable effect, particularly in the Amazon, but in combination with other variables it was small. Deforestation

\begin{abstract}
pressure induced by armed conflict and coca cultivation was highest in Tumaco and Catatumbo regions and in la Macarena, Sierra Nevada and San Lucas mountains-all areas of high biodiversity and conservation importance. In some regions, lack of governance after the peace accords is increasing armed conflict, and our results suggest that those increases in conflict may increase deforestation in those areas (p. 1).
\end{abstract}

Tales conclusiones permiten ir dejando claro que, aunque el conflicto armado no es la única causa de pérdida de la biodiversidad, sí se constituye en un factor determinante para el aumento de la deforestación. Uno de los hechos más preocupantes es que el cultivo de coca, cuya condición de ilegalidad lleva a ubicarle, por lo general, en zonas geográficas de difícil acceso, afecta especialmente áreas boscosas primarias que son fuente de reserva y conservación.

Además de la deforestación, se han producido afectaciones sobre las fuentes hídricas, por la extracción ilícita de minerales y derrames de petróleo, la destrucción de fauna por caza y ganadería extensiva, y cultivos agrícolas sin procesos organizativos o conservacionistas, al igual que por la ocupación masiva de zonas de riesgo en asentamientos urbanos y por desapariciones forzadas y asesinatos de ambientalistas $^{7}$. En la medida en que la guerra se ha intensificado, y que la guerrilla, los paramilitares y las fuerzas armadas estatales han requerido de mayores recursos económicos, se ha intensificado la explotación de dichas fuentes, y los actores armados se han

- Para ampliar el tema de las causas sociales y políticas aunadas al origen del conflicto, es posible consultar el informe Basta Ya, del Centro de Nacional de Memoria Histórica (2013). 
transformado en su explotadores directos (Cárdenas y Rodríguez, 1998).

Después de años de destrucción de los recursos naturales por causa del prolongado conflicto armado, el discurso de la biodiversidad juega un lugar determinante para garantizar la conservación de la naturaleza mediante la creación de una cultura conservacionista. Ahora bien, tal discurso por sí mismo no permite más que la inclusión del componente ecológico en los debates políticos actuales; por tanto, se requiere de una articulación de dicho discurso a través de prácticas sociales y culturales enfocadas en el desarrollo sostenible, en donde la educación ocupe un lugar privilegiado como escenario de aprendizaje de la ciudadanía.

\section{La educación como escenario de encuentro ético con la biodiversidad}

El panorama establecido hasta este punto nos sitúa, como sociedad, frente a la necesidad de crear políticas y estrategias a nivel social, cultural y educativo que propendan por el manejo sostenible de la biodiversidad. Al respecto, Hanson (2019)

A propósito, el informe realizado por el CINEP en relación con la situación de Derechos Humanos en Colombia para el año 2017, plantea que en este período de tiempo se presentaron 56 víctimas individuales y 30 victimizaciones colectivas contra ambientalistas, líderes de restitución de tierra y defensores de derechos asociados a la tierra; situación que expone una correlación estadística aplastante, entre asesinados y desaparecidos, con ciertas zonas de intereses de explotación económica de recursos naturales, ya sea minería, petróleo, aprovechamiento de bosques o expansión agrícola y ganadera. señala que, en un momento de posconflicto, como el presente para Colombia: "hay muchas formas posibles de promover la conservación de la biodiversidad a través de áreas protegidas y la gestión sostenible de tierras públicas y privadas, así como el ecoturismo o las compensaciones por captura de carbono" (párr. 6).

En este sentido, el Estado, las instituciones públicas y privadas y la sociedad civil tienen la obligación de realizar un seguimiento al cumplimiento de los desafíos establecidos en el Acuerdo final para la terminación del conflicto y la construcción de una paz estable y duradera (JEP, 2016) ${ }^{8}$, particularmente en relación con los compromisos socioambientales, dentro de los que se encuentran las políticas de restitución de tierras, la justicia ambiental, la redefinición de los usos del territorio y los derechos de los pueblos indígenas y afrodescendientes.

Esto, junto a otros retos que, pese a no estar explícitos en el documento, requieren de una atención especial para la garantía de una construcción de paz "estable y duradera", como son: la definición e implementación de políticas públicas sobre la materia; la garantía de seguridad a los movimientos ambientalistas y líderes ambientales y sociales; la

\footnotetext{
Además de lo establecido en este acuerdo, es importante recordar que Colombia suscribió el Convenio de Diversidad Biológica a través de la Ley 165 de 1994 (República de Colombia, 1994), con base en la cual formuló la Política Nacional de Biodiversidad y adquirió el compromiso de conformar un Sistema Nacional de Áreas Protegidas. El cumplimiento de estos compromisos sigue pendiente.
} 
estructuración de un modelo de funcionamiento para los servicios ecosistémicos, que sea sostenible en términos ambientales y económicos; la participación ciudadana en la toma de decisiones socioambientales, y la definición de un nuevo ordenamiento territorial, entre otros.

La mejor manera de aprehender la biodiversidad y, a través de esto, mejorar la forma como se vive y habita en el territorio, es a través de la educación. Claramente, no se trata de una formación de tipo bancario o racionalista, sino cercana a la realidad y a sus fenómenos biológicos, sociales y culturales, enfocada en el reconocimiento, validación y resignificación de la diferencia entre los seres vivos y del territorio que habitamos.

Siguiendo a Rozzi, et al. (2005), entonces es fundamental "superar las barreras de aislamiento físico y conceptual" impuestas por la sociedad capitalista, en la cual el acercamiento con la naturaleza se pretende realizar mediante visitas virtuales a sitios de conservación ambiental o a partir de la visualización de documentales ambientales. La recuperación de los encuentros directos con la diversidad biocultural constituye un objetivo fundamental de la experiencia educativa.

Así, en la búsqueda de que los estudiantes perciban, entiendan y redescubran la exuberante diversidad biológica y cultural, es necesario que asuman el encuentro físico con los territorios, es decir, la experiencia vívida de la "singularidad de cada uno de los seres vivos [de este modo] la noción de biodiversidad deja de ser un mero concepto y comienza a ser una vivencia de estar cohabitando entre muchos y diversos seres" (Rozzi, et al. 2005, p. 21).
Como apuesta política, el acercamiento biocultural implica el reconocimiento identitario del sujeto, bajo el encuentro consigo mismo, con el territorio y con otros seres vivos diversos y múltiples, en un proyecto mancomunado que demanda el descubrimiento de la ciudadanía cultural, mediante una experiencia directa con el espacio que, en la medida de lo posible, facilite el proceso de resignificación del territorio. Se trata, de manera explícita, de la formación de ciudadanos como:

[...] agentes sociales que poseen conciencia de su densidad histórica y se autocalifican como tomadores de decisiones a futuro, y responsables de la dimensión política de sus acciones, aunque no puedan calcular ni controlar todas las consecuencias, resonancias o alcances de las mismas (Kriger, 2010, p. 30).

Tales rasgos llevan a que el ciudadano se aproxime críticamente a las condiciones sociales y a las tecnologías de disciplinamiento impuestas por ciertos modelos de sujeto y, en tal sentido, instauran la construcción de nuevas condiciones y oportunidades de ser y estar en comunidad.

Sumado a lo anterior, es importante que los estudiantes se acerquen a la comprensión de las condiciones y prácticas que generan pérdidas ambientales, así como a la conceptualización de las conexiones existentes entre el conflicto armado y la biodiversidad. Recordemos que muchos estudiantes del país pertenecen al grupo poblacional que debió abandonar sus tierras, su comunidad de arraigo rural, a razón de la violencia política y el conflicto; en tal sentido, la experiencia directa con el desplazamiento forzado genera un marco de comprensión que facilita la necesaria discusión sobre estos asuntos. 
Una vez dispuesto dicho marco de comprensión, es esencial instalar experiencias educativas dentro del aula, basadas en la responsabilidad ética, el reconocimiento de los otros y del territorio, el empoderamiento y el agenciamiento político. Este tipo de experiencias permiten regular los conflictos, de manera que se puedan percibir sus aspectos positivos y negativos. Como ya se ha señalado, tales experiencias no se basan en un ser humano abstracto o en la comprensión de un territorio físico lejano de los procesos de significación, sino en un ciudadano cercano a sus realidades sociales, que reconoce críticamente el territorio, sus conflictos y conflictividades.

La educación [...] no puede basarse en una comprensión de los hombres como seres "vacíos" a quien el mundo "llena" con contenidos [...], sino en los hombres como "cuerpos conscientes y en la conciencia como conciencia intencionada al mundo (Freire, 1992, p. 88).

De acuerdo con ello, justamente, la educación no puede basarse en la comprensión de los sujetos como ciudadanos vacíos a quienes el Estado llena de derechos. El ciudadano, además de cumplir deberes, debe garantizar la lucha por el reconocimiento de los derechos negados a otros ciudadanos, así como por la racionalización del conocimiento, especialmente desde el respeto por el conocimiento ancestral y las prácticas culturales de diferente orden.

\section{Conclusiones}

La importancia de establecer, en el campo de la educación, las relaciones entre biodiversidad, conflicto armado y sus secuelas de distinto orden en Colombia, se encuentra en la posibilidad de salir del retraimiento cognitivo y de la reclusión física provocada por las paredes del aula de clases; en su lugar, es importante crear experiencias que propendan por el encuentro biocultural con la realidad, tomando conciencia de las causas de la pérdida de biodiversidad y estableciendo asociaciones entre conflicto, preservación biológica y ciudadanía cultural.

En este sentido, resulta esencial auscultar los vínculos ético-políticos que existen entre la biodiversidad biológica y cultural y el conflicto armado, para lo cual es fundamental dirigir dichos vínculos partiendo de experiencias educativas asociadas con la ética ambiental, entendiendo que es necesaria una transformación en el tipo de interacciones entre el sujeto y su entorno, hacia la producción de relaciones que se sitúen desde la protección de la vida y de los territorios, siempre basándose en el desarrollo sostenible.

Educar para el desarrollo humano sostenible implica formar a ciudadanos y ciudadanas en las habilidades, destrezas, conocimientos y actitudes que contribuyan al máximo desarrollo de sus capacidades para que, de manera libre y autónoma, emprendan un proyecto de vida que les permita contribuir a los cambios necesarios a nivel personal, local, regional y global para fortalecer un modelo de desarrollo comprometido con el ser humano y con la sostenibilidad de las sociedades y del medio ambiente.

Finalmente, la complejidad de los conflictos actuales requiere de un análisis multicausal, de la utilización de enfoques multidisciplinares y de herramientas pedagógicas que faciliten su comprensión, es decir, reinterpretar y reformular los contenidos curriculares, estableciendo relaciones entre el desarrollo, los Derechos Humanos, el medio ambiente y la distribución de la riqueza en las distintas regiones del mundo. 


\section{Referencias}

Aceves, J. (1997). Ciudadanía ampliada. La emergencia de la ciudadanía cultural y ecológica. Revista Razón y palabra, 5(1). Obtenido desde http://www.razonypalabra.org.mx/anteriores/ n5/ciudad.htm

Amórtegui, E. (2020). Biodiversidad fuera del aula: implicaciones didácticas en ambientes naturales y en la formación del profesorado. Trabajo presentado en la Cátedra Doctoral. 2020-1: Educación en biodiversidad. Perspectivas y retos, 2 de junio de 2020, Bogotá, Universidad Pedagógica Nacional.

Cárdenas, M., y Rodríguez, M. (1998). Más allá de los impactos negativos sobre la naturaleza: las complejas relaciones entre guerra, sociedad y medio ambiente. Bogotá: Tercer Mundo Editores.

Cárdenas, M., y Rodríguez, M. (2004). Guerra, sociedad y medioambiente. Bogotá: Foro Nacional Ambiental.

Centro Nacional de Memoria Histórica. (2013). ¡Basta Ya! Colombia: memorias de guerra y dignidad. Bogotá: CNMH.

Centro Nacional de Memoria Histórica. (2017). Una guerra sin edad. Informe nacional de reclutamiento $y$ utilización de niños, niñas y adolescentes en el conflicto armado colombiano. CNMH: Bogotá.

CINEP. (2012). Minería, conflictos sociales $y$ violación de Derechos Humanos en Colombia. Bogotá: Centro de Investigación y Educación Popular-Programa por la Paz (CINEP/PPP).
Collier, P., y Hoeffler, A. (2004). Greed and grievance in Civil War. Oxford Economic Papers, No. 56, pp. 563-595. DOI: https://doi.org/10.1093/ oep/gpf064

Freire, P. (1992). Pedagogía del oprimido. Madrid: Siglo XXI.

Hanson, T. (2019). Lo que las guerras le han causado a la naturaleza, según científico. El tiempo. Obtenido desde https://www.eltiempo.com/vida/medio-amb iente/como-impacta-el-conflicto-armado-al-medioa mbiente-393618\#: :text=El\%20conflicto\%20armado \%20tiene\%20implicaciones,veces\%2C\%20sorprende ntes\%20para\%20la\%20biodiversidad.\&text=Las\%20 guerras\%20erosionan\%20el\%20tejido,humana\%20 en\%20zonas\%20de\%20conflicto

Hanson, T., Brooks, T., Da Fonseca, G., Hoffman, M., Lamoreux, J., y Machlis, G. (2009). Warfare in biodiversity hotspots. Conservation Biology, 23(3), pp. 578-587. DOI: https://doi.org/10.1111/j.15231739.2009.01166.x

Herrera, M. (2006). Ciudadanía social y cultural: perspectiva histórica y retos del aprendizaje ciudadano en el siglo XXI. Revista Ecuatoriana de Historia. Obtenido desde http://repositorio.uasb. edu.ec/handle/10644/1752

JEP. (2016). Acuerdo final para la terminación del conflicto y la construcción de una paz estable y duradera. Bogotá: JEP.

Kriger, M. (2010). Jóvenes de escarapelas tomar: escolaridad, comprensión histórica y formación 
política en la Argentina contemporánea. Buenos Aires: Universidad Nacional de la Plata.

LeBillon, P. (2001). The political ecology of war: Natural resources and armed conflicts. Political Geography, No. 20, pp. 561-584. DOI: https://doi. org/10.1016/S0962-6298(01)00015-4

Marshall, T. H. (1998). Ciudadanía y clase social. Madrid: Alianza Editorial. DOI: https://doi.org/10. $2307 / 40184017$

Martín-Barbero, J. (2003). De los medios a las mediaciones. Comunicación, cultura y hegemonía. Bogotá: Convenio Andrés Bello.

McNeely, J. A. (2003). Conserving forest biodiversity in times of violent conflict. Oryx, 37(02), pp. 142-152. DOI: https://doi.org/10.1017/S0030605303000334

Ministerio de Ambiente y Desarrollo Sostenible. (2002). Política nacional para la gestión integral de la biodiversidad y sus servicios ecosistémicos (PNGIBSE). Bogotá: Ministerio de Ambiente y Desarrollo Sostenible.

Naciones Unidas. (1987). Nuestro futuro común: Informe Brundtland. Obtenido desde https:// undocs.org/es/A/42/427

Naciones Unidas. (1992). Convención sobre la diversidad biológica. Obtenido desde https://www. cbd.int/doc/legal/cbd-es.pdf

Negret, P., Sonter, L., Watson, J., Possingham, H., Jones, K., Suárez, C., Ochoa, J., y Maron, M. (2019).
Emerging evidence that armed conflict and coca cultivation influence deforestation patterns. Conservación biológica, No. 239. DOI: https://doi. org/10.1594/PANGAEA.899573

Rettberg, A., Leiteritz, R., y Nasi, C. (2014). Different resources, different conflicts. A framework for understanding the political economy of armed conflict and criminality in the Colombian regions. Obtenido desde http://ssrn.com/abstract=2499580 DOI: http://dx.doi.org/10.2139/ssrn.2499580.

República de Colombia. (1994). Ley 165 de 1994. Bogotá: Diario Oficial.

Rodríguez, C., Rodríguez, D., y Durán, H. (2017). La paz ambiental: retos y propuestas para el posacuerdo. Bogotá: Antropos. DOI: https://doi.org/10.15359/ rca.52-1.10

Ross, M. (2002). Natural resources and civil war: An overview. World Bank Reasearch Observer, pp. 1-37.

Rozzi, R., Draguicevic, J. M., Arango, X., Sherriffs, M., Ippi, S., Anderson, C., Acevedo, M., Plana, J., Cortés, E., y Massardo, F. (2005). Desde la ciencia hacia la conservación: el programa de educación y ética ambiental del Parque Etnobotánico Omora. Revista Ambiente y Desarrollo, 21(2), pp. 20-29.

Sloan, S., Jenkins, C., Joppa, L., Gaveau, D., y Laurance, W. (2014). Remaining natural vegetation in the global biodiversity hotspots. Biological Conservation, No. 177, pp. 12-24. DOI: https://doi. org/10.1016/j.biocon.2014.05.027 